\title{
Administrative workplaces in healthcare: Designing an efficient and patient-focused environment
}

\author{
Peter Fröst* \\ Department of Architecture, Chalmers University of Technology, Sweden
}

Received: February 21, 2016

DOI: $10.5430 /$ jha.v5n4p68

\author{
Accepted: April 29, 2016 \\ URL: http://dx.doi.org/10.5430/jha.v5n4p68
}

\begin{abstract}
The article presents an "Evidence-Based Concept Program" for the administrative workplaces in healthcare. Several studies show that Swedish doctors and nurses use about half their working time on administrative work. Despite this, very little attention has been given to the design of administrative workplaces in healthcare. Although healthcare focuses on detailed functional planning of their clinical areas, administrative workplaces are typically designed very traditionally, supporting hierarchical and downpipe organisations. Consequently, they are not always supportive of today's healthcare needs, which focus on teamwork around the involved and informed patient. This makes provision of healthcare less efficient and patient friendly. However, new technologies and new ways of working means that the conditions for administrative/office work have changed drastically in recent decades. It is therefore time to seek inspiration from other sectors of society so as to rethink healthcare design. Conclusive report findings indicate that a changed approach needs to be introduced to the design of administrative workspaces. Mapping exercises of existing conditions show low utilisation of non-care-related administrative workplaces. These workplaces can be made more efficient by organising the plan according to activity-based usage and thereby reducing the area needed. Included survey also indicate that the degree of utilisation of administrative workplaces close to patients is relatively high. The report concludes that patient-related administrative workplaces need to be developed further through adding new room types and number of functions. Unused space can be redistributed to care located closer to patients, as the need is greater and this will help promote work efficiency. However, the design of new and more activity-based administrative workplaces in healthcare relies heavily on the introduction of new portable and seamless information and communication technology (ICT)-systems.
\end{abstract}

Key Words: Healthcare, Administrative workplaces, Activity-based design, Evidence-Based Concept Programs

\section{INTRODUCTION}

The content, form, and location of administrative work have undergone dramatic changes in recent decades. The reasons for this are several. One is the new way that we organise information work due to new information and communication technology (ICT). It also means that administrative work has become much more effective. As a result of the latest portable technology, it can also be more mobile. The notion of the private office or desktop as a natural place for most tasks is replaced by a broader perspective. Today, a repertoire of possible solutions, locations, and functions where our administrative work are performed can be seen. Measurements regularly show that the personal desktop is utilised about one-third (1/3) of the work day. The rest is carried out in other rooms or locations. The role of "the Office" has become a meeting place, where cooperation and knowledge sharing are central.

In healthcare, the rate of change within administrative work-

*Correspondence: Peter Fröst; Email: peter.frost@ chalmers.se; Address: Department of Architecture, Chalmers University of Technology, Sweden. 
places is slower than in other sectors. There, private offices for doctors, experts or managers and shared office rooms or workstations for other professions dominant are found. Simultaneously, administrative work today in healthcare is so time-consuming and extensive that it detracts from time spent with patients. Several studies show that for Swedish doctors and nurses, as much as half their time is spent on administration.

The Swedish Agency for Health and Care Services Analysis concludes ${ }^{[1]}$ that Sweden, in an international perspective, is well-staffed with doctors and is one of the Organization for Economic Cooperation and Development (OECD) countries that have the highest number of doctors per thousand inhabitants (3.9 MD/1,000 inhabitants, average OECD 3.1 M /1,000 inhab). However, the number of medical visits per inhabitant per year is few, far lower than the average in the OECD (3 visits/capita in Sweden, average OECD 7.1 visits/capita). According to a comparative study, ${ }^{[2]}$ doctors in Sweden spend about $51 \%$ of his/her time on administrative work and $40 \%$ on patient work. This research has been investigated by others and will not be included in this article.

As a pre-study to this report, an expert seminar with facility planners, researchers, healthcare staff and architects was performed at Chalmers in April 2012. One conclusion reached was that in order to modernise administrative workplaces in healthcare, new types of office solutions need to be explored. They must support new and various needs while avoiding the usual adverse effects that are identified in research. This is also summarised in a number of goals for healthcare administrative workplaces: ${ }^{[3]}$

- Support doctors, nurses and other health professionals so that the administrative work can be facilitated such that there will be more time for direct patient care.

- Promote a good working environment. Stress, noise, awkward postures, upright working and a lot of walking are examples of work environment problems for healthcare professionals. Some of these problems are caused by administrative workplaces that are wrongly located, designed and equipped.

- Facilitate modern and efficient working methods. Several Swedish hospitals today are presenting major efficiency gains due to improved work. Good organization, efficient processes and ICT systems with properly designed administrative spaces can support new ways of working and enable rational flows.

\section{OBJECTIVE}

This article presents the results from a report about administrative workplaces in healthcare. It has been produced by the Centre for Healthcare Architecture at Chalmers University of
Technology in Gothenburg, Sweden, in collaboration with a national network (PTS) consisting of 15 (out of 21) Swedish County Councils.

In the report, administrative work in healthcare is defined as consisting of two types - "Patient-related administrative work": is the management of information needed to make decisions about the patient. This includes fex phone calls, documentation of test results and medical records. "Other administrative work": includes the different tasks to support, and manage healthcare operations. These types are performed in different places and situations in healthcare: (1) Administrative work in the direct care work - refers to flexible or fixed workplaces, primarily needed for patientrelated administration. These workplaces are always included in the department/clinic and consists of workstations, team-room, workplaces inside the patient room/treatment rooms for documentation etc., reception areas and in some cases care administrator's workplace; (2) Administrative work in indirect care work - refers to workplaces where administrative and healthcare knowledge are exchanged (not near patient). These workplaces are usually found close to, but not necessarily inside, the department/clinic. These are typically medical offices, meeting and study rooms.

The report is a set of planning tools that consists of visualised design concepts and explanatory text. It was published in Swedish on the networks homepage January 2015 and is now being applied in several Healthcare projects around Sweden. ${ }^{[4]}$ The report is included in a series of "EvidenceBased Concept Programs for Healthcare Architecture" that recently have been developed in Sweden. ${ }^{[5]}$ The concept program concerning administrative workplaces described in this article, is the third in a series and contains a research review and a survey as well as motivated conclusions and illustrated proposals for how to design future administrative workplaces. Their purpose is to facilitate implementation of both evidence and best practice in a today's planning process. The current dynamic planning model in healthcare needs to integrate staff participation and dialogue with systematically processed best practice and evidence-based knowledge. The concept programs are meant to be utilised as tools for supporting discussions rather than as traditional guidelines or solutions to copy. The purpose is to form a basis for the planning dialogue in the collaboration process in each particular project.

\section{Methods}

The report is based on three knowledge surveys - a research review and a survey of how health care administrative premises are used and perceived today in Sweden (addition- 
ally, a survey with inspiring examples of best practice in Sweden and internationally, which is not included in this article).

\subsection{Research review}

The purpose of the research review was to highlight findings that can support the design of future administrative workplaces in healthcare is becoming increasingly evidencebased. It is structured around a number of design factors that are linked to available research. Design factors - such as health and stress, ${ }^{[6]}$ cooperation, ${ }^{[7]}$ daylight, ${ }^{[8-10]}$ access to nature, ${ }^{[11]}$ noise, ${ }^{[12,13]}$ indoor climate ${ }^{[14]}$ etc., is grounded on a selection of relevant scientific studies. It has been found that very few studies or research summaries have been done in the field of healthcare administrative workplaces. However, there are a number of studies from healthcare environments where administrative work is involved. ${ }^{[15,16]}$ Research on office environments is in itself a major area in many scientific fields. A selection of these, together with research on healthcare environments, is the core of the research review.

The research review shows that there are a variety of office types with different properties that are experienced as both positive and negative. ${ }^{[17]}$ Office types that have been studied are private offices, shared offices, small offices (3-10 pers.), mid-sized offices (10-20 pers.), large offices (20-up) and activity-based-office (ABW). Research also shows that if you have a good physical office / administrative environment you are also more satisfied with the psychosocial work environment and higher job satisfaction is reported ${ }^{[18]}$ One hypothesis is that the physical environment is interpreted as an indicator of the organisation and the management's commitment to employees. It is important not to see administrative workplaces only as a choice between private office, shared office or open office. One of the most prominent problems in open offices is noise and lack of privacy. Research has shown that what is most disruptive is not the loudest noise but voices, phone conversations and other meaningful information from other colleagues. ${ }^{[19]}$

An overall conclusion of some recent comprehensive Swedish studies is that office type itself has a major impact on health status, sick leave and satisfaction with the working environment. ${ }^{[20]}$ The results showed that when it comes to sick leave, private office and $\mathrm{ABW}$-office stood out as types where employees had the best health. Small and medium sized open offices (3-10 resp. 10-20 pers.) were the worst. When it comes to perceived health, which is important when it comes to stress, were ABW-office best and private office second best. In this instance, small and medium-sized open offices performed worst. Another study also suggests that the office type affects the experience of leadership. The greatest dissatisfaction with the leadership was experienced in a shared room (2-3 persons/room). One possible explanation for this could be that a subculture develops easily in small groups and persons working there develop barriers between those "in the room" and the ones "outside the room".

Private office and ABW office are significantly better than other office types when it comes to job satisfaction and satisfaction within the office environment. Those who were most satisfied with their physical environment were those who worked in a private office. For togetherness, fellowship and cooperation, however, the private offices were the least supporting option. Here, the activity-based office was best. In $\mathrm{ABW},{ }^{[21]}$ individual fixed workplaces don't exist. Instead the whole administrative environment is designed as a repertoire of different workplaces that support the actual needs of the moment. One can work in groups, individually or concentrated depending on changing needs. At the same time the environment can enable spontaneous meetings and interaction.

\subsection{Surveys}

Four surveys of existing conditions in Swedish healthcare were conducted over a year, from December 2013 to December 2014. Four different methods (qualitative and quantitative) have been used - participatory observation, frequency-of-use mapping, an online questionnaire and a cross-disciplinary workshop. The purpose was to understand how healthcare administrative work environments look like today and how they are used. Key questions posed were: How and how frequently are the administrative premises used and how do they function during the workday? The double aims of the online survey and the workshops have also been to look ahead and map what is considered important for the future.

\subsubsection{Qualitative method surveys - participatory observa- tion and interviews}

The survey began with six participatory observation studies in three geographically diverse hospitals in Sweden - two university hospitals and a medium-sized regional hospital. In the observation studies, the observer documented all administrative duties that the doctor or nurse performed noting the location and duration of the performed tasks. In relation to some of the observations, an additional short interview was also conducted with the involved doctor or nurse. The purpose was to get a better understanding of all aspects of the respondents' administrative work and how the premises actually supported that as well as to deepen and clarify the results from the other parts of the investigation. 


\subsubsection{Quantitative method surveys - web survey and frequency-of-use mapping}

The second part was designed as quantitative method studies - a web survey and a frequency-of-use mapping. The online survey was sent out to the four participating County Councils, including three of the hospitals that had been covered by the previous participatory observation studies. It consisted of 16 questions including hospital, profession, age, gender. In the online survey the respondents estimated how they use their administrative workplaces and rank them (translated from Swedish). "Identify the administrative workplaces you use in your work and estimate how many percent of your work that you spend there" (fourteen different options where given as private or shared office, workstation in consultation or ward, team-room, meeting-room, study-room). It also had a qualitative part. Examples of questions where:

- "How does your main administrative workplace supports the tasks you perform there?"

- "Is your main administrative workplace well located in relation to your other duties?"

- "Does your main administrative workplace support your need for concentrated work?"

- "Does your main administrative workplace support your needs for communication and knowledge sharing?"

The survey ended with an open question where the participants were asked to "Describe how your future ideal administrative work place would look like? How could it be designed and situated? What tools (ICT) and support system would it have?" The web questionnaire had a response rate of $48.5 \%$ (514 out of 1,058 completed the survey). The study was not randomized - the participating County Councils had selected the clinics.

In the frequency-of-use mapping, we studied how much different types of administrative workplaces in health care actually were utilized. It included two university hospitals, two mediums sized regional hospitals, and one smaller local hospital. The study lasted for three weeks in four different Swedish County Councils. A total of 27 departments were observed for 3 weeks, 3 times a day. This gave 1,072 times (as some occasions newer happened depending on sick leave etc.). A total of 885 workstations where mapped. These included clinics, wards and administrative units in the hospitals but also purely administrative buildings. The mapping also identified if the different workstations where affected by the location and distance between the workplace and respective clinic/unit.

\subsection{Workshops and summary}

To promote innovation within administrative workspace planning, a workshop was arranged at the Centre for Healthcare Architecture at Chalmers University of Technology in April 2014. A total of 35 representatives comprising 15 county councils, architects and researchers, participated in the workshop. Results from the research review and the surveys (participatory observation studies, interviews, online survey and frequency-of-use mapping), together with examples of best practice, were presented at this cross-disciplinary workshop. The results from the workshop have been evaluated and processed by the project team and Chalmers research group. This formed a starting point for the development of a series of illustrated proposals.

\section{RESULTS}

The results from the participatory observations support results from other surveys and studies that healthcare staff in Sweden spend a lot of time on administration. For example, a nurse in a university hospital surgery ward had 79\% administrative tasks during a shift. Another nurse on a comparable ward at a regional hospital had $78 \%$ administrative tasks. (The nurse at the university hospital used a workstation in the central nurses' office most while the nurse in the regional hospital used the decentralised workstation and team room the most). In the outpatient Gynaecology department in a university hospital, another nurse spent $51 \%$ on administrative work. Within the surgery outpatient department in a mid-sized hospital another nurse performed 50\% administrative tasks. A doctor, working in a medical ward at a university hospital in the morning and with outpatient reception in the afternoon, had $68 \%$ administrative tasks during such a workday.

The interviews confirm that many professions in healthcare (doctors, nurses, assistant nurses, etc.) perform a large part of administrative work and, therefore, need supportive and easily accessible administrative workplaces. It also identified a need for workplaces where administration could be carried out in peace and quiet, something often found lacking in today's healthcare environments. Different facilities for teamwork and support should resemble one another within a hospital. The reason is that nurses and assisting nurses often change teams in the wards/clinics. Doctors and other professions in healthcare (such as physiotherapists, nutritionists and paramedical) change wards/clinics several times a day.

The majority of respondents in our web survey answered that they are satisfied with their administrative workplaces. Just over two-thirds of doctors (68\%) responded that they think that their administrative work in the direct patient work supports their needs. An overwhelming majority in the different 
professions (82\%-90\%) responded that they believe that their administrative workplaces support the need for communication and knowledge sharing. There are, therefore, aspects that works well today that can be developed further. The answers show that a majority of doctors estimate that they use their office $30 \%$ or less. While a majority of medical secretaries and administrators estimate that they use their office $60 \%$ or more.

The open question ("Describe how your future ideal administrative work place would look like? How could it be designed and situated? What tools [ICT] and support system would it have?") gave many expected answers. The respondents are complaining over old fashioned (stationary computers) and insufficient ICT-systems that hinders flexibility. A majority wants a private office with an adjustable desk and good ICT. Daylight, good ventilation, lighting and acoustics are also important issues that are raised. But many answers also pointed to possible developments for the future. Several of the respondents wants more flexibility for different work situations i.e. with and without patients. Doctors points out that they move around much in the hospital. They work $f$ ex in the emergency department, in the outpatient unit and in the ward. And often on the same day. Most of them have a personal office, private or shared with others, but spend only short time there for purely administrative tasks and do not use it for the daily management of patients. For some of them, a future ideal administrative work place would mean (translated from Swedish): "Ability to use a workplace that fits the tasks for today. If I have to write a lot and be concentrated, I want to be able to work undisturbed and alone. If I am to work in a team, I want to be able to sit with everyone in the team. If I'll edit images, I want to have a station for it with the right equipment that functions well. If I'm going to have a short meeting, is it is important that there is a meeting room with the right equipment (computer and large screen)." And: "The ideal future workplace is based on a portable work tablet, with which actually all work would be carried out, but for confidentiality, dictation must be done in closed rooms, but would also be possible in the portable work tablet. Since then, you really have the office in your pocket and becomes less dependent on a personal workplace. As long as we are dependent on paper in any form, the personal workplace will remain. It will, as seen above, yet require a number of rooms with closed doors which need not be personal. Open plan offices will not work for this work."

The frequency-of-use mapping indicates that administrative workplaces in healthcare are utilised between 10\%-60\%. The mean utilisation is $30 \%$ (35\% if purely administrative buildings, like hospital management etc, are included). It was observed that the utilisation of workplaces for indirect pa- tient work is very low. The lowest use was found among the administrative premises that are not in connection with the ward or clinic as for example on another floor or building. Here, the mapping provides an observed use of only $10 \%-15 \%$. In contrast, direct patient related administrative workplaces had a much higher usage at around 30\%-60\%. The relatively low utilisation rates can be seen as a paradox when we know that healthcare staff in Sweden spends a lot of time on administration. A possible explanation is the uneven distribution of utilisation. The very low level use of workplaces for indirect patient work (e.g. doctors' offices) pulls down this average, while workplaces near the direct patient work has a significantly higher utilisation.

\section{Discussion}

In addition to research review, surveys and overviews of good examples, the report "Evidence-Based Concept Program for administrative workplaces in healthcare" also contains illustrated proposals for how to design future administrative workplaces. As mentioned earlier, they should be seen as inspiring tools for discussions in the planning and design process rather than as solutions to copy. The reason why illustrated proposals were chosen, and not just text is based on a "Design thinking" approach. ${ }^{[22,23]}$ The design process needs to be tailored to suit healthcare's evolving needs. Conceptual models developed during the building's planning process emerge from collaboration and dialogue between architect and different user groups. Requirements and needs are identified and formulated while spatial solutions are worked out. In Sweden, the architectural planning process is typically structured around staff participation. This involves discussing work processes, formulating goals, identifying functional needs and relationships, and developing solutions. To facilitate this, it is very efficient to work with concrete visual methods - for example illustrated proposals that can promote dialogue. Such an approach, which expands the traditional planning with various tools and activities, supports jointly formulated goals, identifies spatial needs, and develops and evaluates ideas. In this way, the design process provides an opportunity for staff to learn more about their own work by being active participants in the design. ${ }^{[24,25]}$

In healthcare today the office room - individual or shared is the dominant solution for most administrative needs. Research confirms that this room type is appreciated, and when it is private, also works well in many other ways. However, the private office has weaknesses and disadvantages. Research shows that it is an inferior office type when it comes to supporting communication and team-building. The individual private office typology takes up precious floor space and areas with natural daylight (very important in the Swedish 
context). The risk is that it displaces other more important hospital functions to less ideal environments that are lacking in daylight and views. The research review demonstrates the importance of access to daylight and views of nature to counteract stress.

In open office plans, research show that several of its variants have significant shortcomings regarding, for example, noise, stress and difficulty concentrating. It is worth noting that office rooms with more than four persons is sometimes characterised as a small open-office among researchers. This is partly based on factors such as group size etc. Furthermore, several research studies have highlighted that open office solutions are not as beneficial to collaboration and knowledge sharing as previously thought.

This research supports the assumption that the concept of activity-based administrative workplaces in healthcare ABW - could function well, even if it is an office type with some disadvantages. It is an office type that is appreciated and also has good results on many other parameters in research studies. Possible explanations are that it promotes (and build on) a high degree of self-control. There is a freedom to choose one's workplace and, thus, the degree of privacy. Studies also show that the process of introducing activity-based office is important. Systematic activity mapping involving surveys and task analyses is recommended. Staff participation in this process is also crucial for a successful result. ${ }^{[26]}$

ICT systems in healthcare need to be improved in order to allow for more flexible and effective work performance. Our survey confirms that ICT systems constitute a major problem in Swedish healthcare. Various ICT systems used within different departments/clinics and incompatible system functions create frustration, inefficiency and wasted time. The successful implementation of the proposals contained in the report and activity-based administrative workplaces are reliant on compatible ICT systems. This means big investments, both in terms of time and money. However, this report does not include suggestions on how to change the ICT system.

\section{RECOMMENDATION}

\subsection{Recommendation 1: include administrative work in the functional planning process}

In modern times, the diversification and development of healthcare and healthcare buildings have resulted in an increasing number of specialties. Today's hospitals therefore contain an entire repertoire of rooms with different functions. Administrative work, on the other hand, has until now not been considered in this manner. It has been assumed that current and traditionally limited types of administrative workplaces - offices, workstations and meeting/study rooms, meets all specialized needs. Firstly, this is partly due to specialised conditions in healthcare. Secondly, the healthcare system has not taken the opportunities on offer. The report recommends the same high level of ambition in the functional planning of administrative workplaces as in other healthcare facilities. A comprehensive and differentiated description of activities and functions required should be included in the design process.

\subsection{Recommendation 2: introduce an activity-based ap- proach also to administrative workplaces}

Administrative workplace design should be adapted to function and be activity-based as apparent in clinical areas in healthcare facilities. Administrative work environments need a variety of room types, furniture and equipment, and is tailored to specific user needs. Today's healthcare provision is activity-based and the design of modern healthcare facilities is focused on solving the needs of these different activities. The report recommends that administrative work settings in healthcare need to be diversified from offices, workstations and meeting rooms to a palette of administrative work activities (see Figure 1).

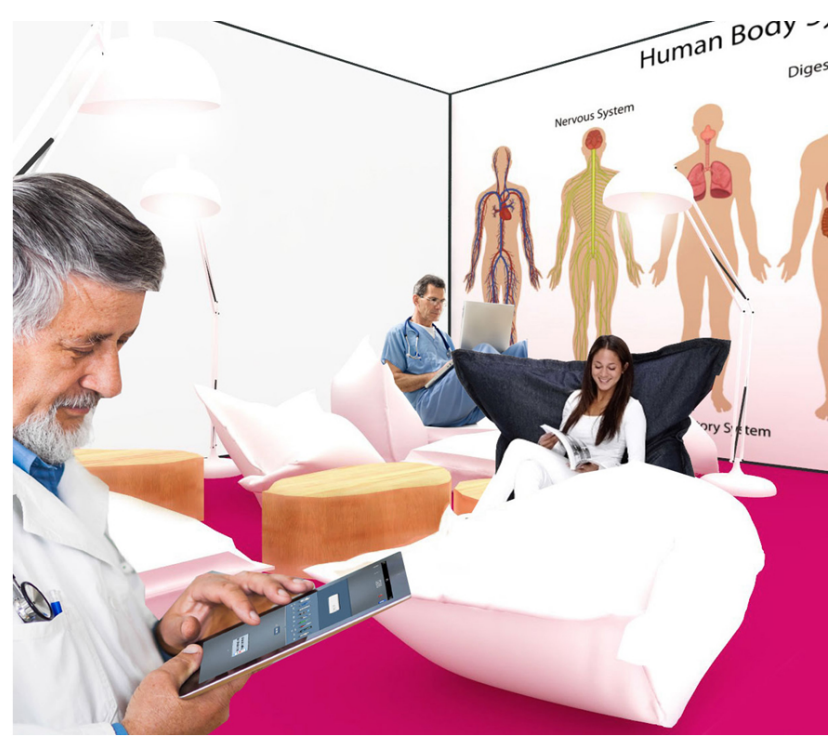

Figure 1. Activity-based Staff Lounge, a visionary illustration

\subsection{Recommendation 3: increase administrative work- places in the direct care work}

Administrative workplaces in the direct care work need to be developed by being more accessible, differentiated and promoting team-work. Person-centered care philosophy involves close collaboration around the patient. This implies the need to work with information and documentation contained in the patient room and to create team-areas close to 
the direct patient work. The report recommends designing smarter administrative workplaces that places all health care professions and team collaboration near patient's areas. In this way multi-professional and cross-disciplinary cooperation can be strengthened (see Figure 2).

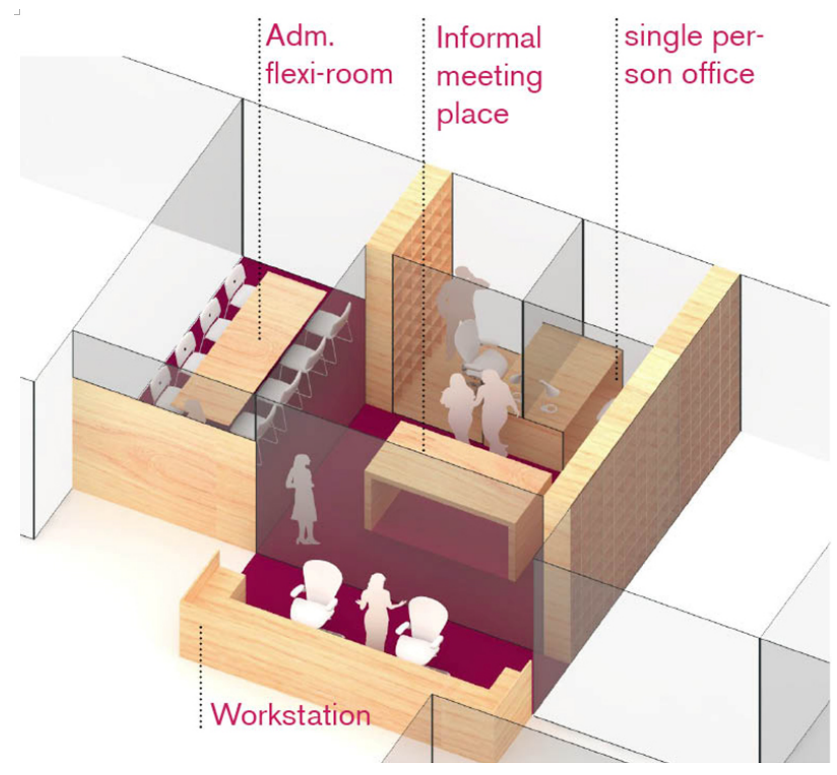

Figure 2. Administrative workplace for ward team

\subsection{Recommendation 4: reduce and reorganise adminis- trative areas for indirect care work}

Administrative areas for indirect care work can be reduced, reorganised and simultaneously be made more attractive. Results from questionnaires and frequency-of-use mapping indicate that the utilization of workplaces, intended for the indirect care work, is very low. These facilities currently consist mainly of cellular offices (mostly private) or shared rooms. Lowest use was recorded amongst administrative facilities on another floor or building. The report recommends that these administrative units be designed as activity-based administrative workplaces for all professions in healthcare. Consequently, the utilisation ratio can be increased to a more reasonable level. Unused surface can thus be redistributed to administrative workplaces close to the patients (see Figure 3).

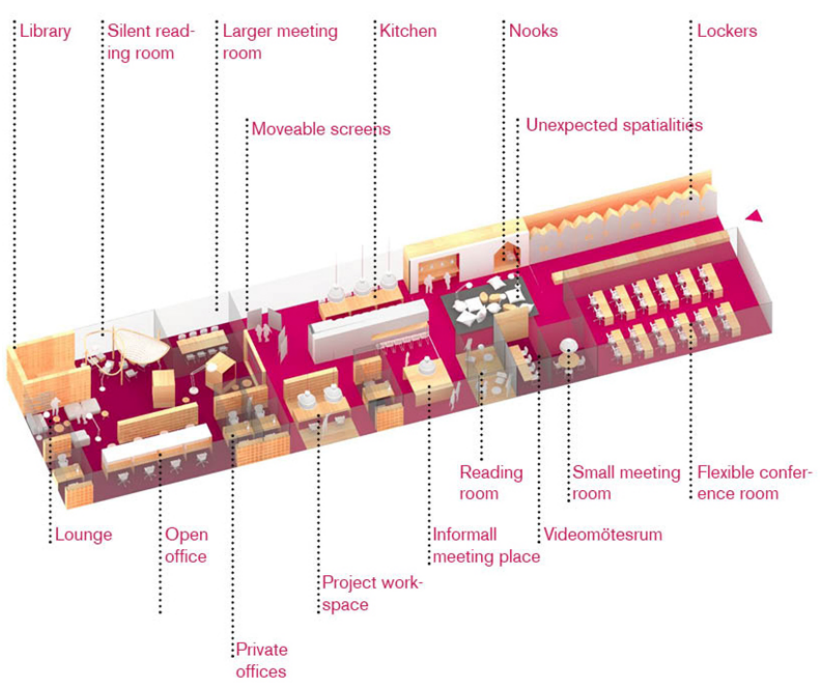

Figure 3. Administrative area for indirect care work and multi professional collaboration

\section{Conclusions}

Administrative workplaces in healthcare today, as shown and discussed in this article, have potential for improvement. When doctors and other healthcare staff are spending increasing amount of their time on administration, it is found that these administrative spaces are inappropriate, misplaced or underutilised. Administrative workplaces are still designed very traditionally, supporting hierarchical and downpipe organisations. They are, accordingly, not always supportive of today's healthcare with a focus on teamwork around the involved and informed patient and more portable ICT systems.

However, a modernised approach and new designs are unable in itself to make the change. Good workplaces can support staff and allow administrative work environments to be more efficient, provide more time for patients and foster a positive working environment. The traditional solutions in healthcare environments need to be challenged by new approaches, new knowledge and new attitudes. At the same time, it is always important to take healthcare's special conditions such as confidentiality and patient privacy, into account.

\section{CONFlicts OF InTEREST Disclosure}

There are no competing interests in this paper.

\section{REFERENCES}

[1] Vårdanalys. Ur led är tiden. Fyra utvecklingsområden för en mer effektiv användning av läkares tid och kompetens ("Time is out of joint" - four development areas for a more efficient use of physician time and skills). Rapport. 2013: 9.

[2] Edvardsson J, Arnholdt-Olsson A, Jeppson B. Mer tid för patienten hos läkare i England En jämförande tidsstudie av svenska och engelska läkares arbetsdag (More time for the patient to a doctor in England, a comparative term study of English and Swedish doctor working). Läkartidningen (Journal for Swedish Doctors). 2014; 111.

[3] Karlson B. Kontorsmiljöer - effekter på arbetstillfredsställelse, hälsa och prestation (Office Environments - effects on job satisfaction, 
health and performance). Lecture at seminar concerning informationand office environments in healthcare 2012-04-19, Chalmers University of Technology, Gothenburg. 2012.

[4] Forskning och Framtid. Administrativa arbetsplatser i vården och dess förvaltningar (PTS Program for Technical Standard. Administrative worlplaces in healthcare and its administrations). Chalmers and PTS. 2015. Available from: https://www.ptsforum.se/fo rskning/administrativa-arbetsplatser/

[5] Fröst P. Evidence-based Concept Programs for Healthcare Architecture. In Verma, I. \& Nenonen, L.(edit.). ARCH14 International Conference on Health Care Architecture. Conference proceedings. Aalto University School of Arts, Design and Architecture. 2015.

[6] Sundstrom E. Work places: the psychology of the physical environment in offices and factories. New York: Cambridge University Press; 1986.

[7] Becker F. Nursing Unit Design and Communication Patterns: What Is "Real" Work? HERD. 2007; 1(1): 58-62. PMid: 21157718. http://dx.doi.org/10.1177/193758670700100115

[8] Begemann SHA, Van den Beld GJ, Tenner AD. Daylight, artificial light and people in an office environment, overview of visual and biological responses. International Journal of Industrial Ergonomics. 1997; 20(3): 231-239. http://dx.doi.org/10.1016/S0169-8 141 (96) 00053-4

[9] Finnegan MC, Zener Solomon L. Work attitudes in windowed vs. windowless environments. Journal of Social Psychology. 1981; 115: 291292. http://dx.doi.org/10.1080/00224545.1981.9711674

[10] Alimoglu MK, Donmez L. Daylight exposure and other predictors of burnout among nurses in a university hospital. International Journal of Nursing Studies. 2005; 42(6): 549-555. PMid: 15921986. http://dx.doi.org/10.1016/j.ijnurstu. 2004.09.001

[11] Dravigne A, Waliczek TM, Lineberger RD, et al. The effect of live plants and window views of green spaces on employee perceptions of job satisfaction. HortScience. 2008; 43(1): 183-187.

[12] Evans GW, Johnson D. Stress and Open- Office Noise. Journal of Applied Psychology. 2009; 85(5): 779-783. http://dx.doi.org /10.1037/0021-9010.85.5.779

[13] Kaarlela-Tuomaala A, Helenius R, Keskinen E, et al. Effects of acoustic environment on work in private office rooms and openplan offices-longitudinal study during relocation. Ergonomics in Design. 2009 Nov; 52(11): 1423-1444. PMid: 19851909. http: //dx.doi.org/10.1080/00140130903154579

[14] Witterseh T, Wyon DP, Clausen G. The effects of moderate heat stress and open-plan office noise distraction on SBS symptoms and on the performance of office work. Indoor Air, 14(s8), 30-40. innovation. Environment and Behavior. 2004; 41(3): 427-442.
[15] Simmons M. Designing wards to release time to care. Nursing Times. 2011; 107(21): 2 .

[16] Mroczek J, Mikitarian G, Vieira E, et al. Hospital design and staff perceptions. The Health Care Manager. 2005; 24(3): 233-244. PMid: 16131934. http://dx.doi.org/10.1097/00126450-2005070 00-00008

[17] De Croon EJ, Sluiter JK, Kuijer PPFM, et al. The effect of office concepts on worker health and performance: a systematic review of the literature. Ergonomics. 2005; 48(2): 119-34. PMid: 15764312. http://dx.doi.org/10.1080/00140130512331319409

[18] Sundstrom E, Town JP, Rice RW, et al. Office noise, satisfaction, and performance. Environment and Behavior. 1994; 26(2): 195-222. http://dx.doi.org/10.1177/001391659402600204

[19] Haka M, Haapakangas A, Keranen J, et al. Performance effects and subjective disturbance of speech in acoustically different office types-a laboratory experiment. Indoor Air. 2009 Dec; 19(6): 454-67. PMid: 19702627. http://dx.doi.org/10.1111/j.160 0-0668.2009.00608.x

[20] Bodin Danielsson C. The Office, an explorative study. Architectural Design's Impact on Health, Job Satisfaction \& Well-being. Dissertation KTH. 2010.

[21] Appel-Meulenbroeck R, Groenen P, Janssen I. An end-user's perspective on activity-based office concepts. Journal of Corporate Real Estate. 2011; 13(2): 122-135. http://dx.doi.org/10.1108/1 4630011111136830

[22] Fröst P. Designdialoger i tidiga skeden. Arbetssätt och verktyg för kundengagerad arbetsplatsutformning (Design Dialogues in early stages of building projects. Methods and tools for customer engaged workplace design). Dissertation in Swedish. Gothenburg, Chalmers University of Technology. 2004.

[23] Carlgren L. Design thinking as an enabler of innovation: Exploring the concept and its relation to building innovation capabilities. Göteborg, Chalmers University of Technology, Dissertation; 2013.

[24] Fröst P. Representing Space - Designing Arenas for Human Action, in Design Spaces, Ed Thomas Binder, Maria Hellström. Finland: Edita IT-Press; 2005.

[25] Elf M, Fröst P, Lindahl G, et al. Shared decision making in designing new healthcare environments - time to begin improving quality. BMC Health Services Research. Quality, performance, safety and outcomes. 2015; 15(1): 1-7.

[26] Gorgievski M, van der Voordt T, van Herpen S, et al. After the fire, New ways of working in an academic setting. Facilities. 2010; 28 (3/4): 206-224. http://dx.doi.org/10.1108/0263277101102 3159 